\title{
Determination of Formaldehyde Content in Wet Noodles by Thin Layer Chromatography-Densitometry After Derivatization With Nash Reagent
}

\author{
HAYUN HAYUN ${ }^{1 *}$, KADEK HARMITA $^{1}$, and TRI BAWONO PRAMUDITA ${ }^{1}$ \\ ${ }^{1}$ Faculty of Pharmacy, Universitas Indonesia, Depok, West Java, 16424, Indonesia. \\ ${ }^{*}$ Corresponding author Email:hayun.ms@ui.ac.id \\ http://dx.doi.org/10.13005/ojc/330341
}

(Received: April 22, 2017; Accepted: May 19, 2017)

\begin{abstract}
Determination of formaldehyde content in wet noddles using thin layer chromatography (TLC) densitometric method after derivatization with Nash reagent has been developed. The calibration curve in the concentration range of 4 to $40 \mathrm{ng} / \mathrm{spot}$ showed good linier relationship $(r=0.999)$. The limit of detection and quantitation (LOD and LOQ) were 1.75 and $5.29 \mathrm{ng} / \mathrm{spot}$, respectively. The method gave satisfactory selectivity, linierity, precision and accuracy validation criteria and was applied for determination of formaldehyde content in three wet noodles samples products purchased from traditional market in Depok City, West Java, Indonesia. Results of the determination showed that all samples were detected containing formaldehyde with the concentration of $990.94,801.80$ and $1684.36 \mathrm{mg}$ formaldehyde per $\mathrm{kg}$ samples.
\end{abstract}

Keywords: Formaldehyde; Wet noodles; Nash reagent; TLC-Densitometry.

\section{INTRODUCTION}

Formaldehyde ( $\mathrm{HCHO})$, known by its systematic name methanal, is an important chemical for the global economy, widely used in construction, wood processing, glues and adhesives, textiles, and in the chemical industry ${ }^{1}$. When dissolved in water it is called formalin, which is commonly used as an industrial disinfectant, and as a preservative in funeral homes and medical labs. However, food manufacturers in some countries sometimes illegally use formaldehyde as a preservative in foods to extend its shelf-life ${ }^{3-8}$. Some studies of humans have suggested that exposure of the compound is associated with increased risks of leukemia, particularly myeloid leukemia ${ }^{1-2}$, therefore, all countries in the world prohibit the use of formaldehyde as a food preservative. Because of its toxicity, determination of formaldehyde content in food samples is a very important task.

Several analytical methods are available for determination of formaldehyde after derivatization, such as spectrophotometry, high performance liquid chromatography (HPLC) and gas chromatography (GC). Formaldehyde is derivatized with $\mathrm{Nash}^{3-4,9}$ 
or Fluoral $\mathrm{P}^{10-11}$ to form a yellow species in solution monitored at $412 \mathrm{~nm}$, with chromotropic acid to produce a purple species in solution monitored at $580 \mathrm{~nm}^{12}$ and with dimedone (5,5-dimetil-1,3sikloheksadione) to form formaldemedone monitored at $254 \mathrm{~nm}$ or as flourescent derivative having an excitation wavelength of $395 \mathrm{~nm}$ and an emission wavelength of $463 \mathrm{~nm}^{13}$. The spectrophotometric method is simple, rapid, economical, and highly sensitive, but the reagents are sensitive not only to formaldehyde, but also to other aldehydes and if chromophore compounds are present in the samples, they could interfere those spectrophotometric determination. Some substances with chromotropic acid can liberate aldehydes in an acid medium and give a false-positive test ${ }^{14}$. HPLC and GC methods have been used to enhance the selectivity of the formaldehyde determination methods ${ }^{7,8,15}$, but those methods are more costly. Alternative chromatographic method with lower operational cost is thin layer chromatography (TLC) densitometric method $^{16}$, but only few reports on the determination of the compound in foods using this method ${ }^{17-19}$, and no report on the determination of the compound in wet noodles using the method after derivatization with Nash reagent.

Noodles are one of the most popular Indonesian foods. In West Java province for example, more than 200 tons of wet noodles are being sold every day ${ }^{20}$. Unfortunately, this food is often found to be added formaldehyde illegally, especially those sold in traditional markets ${ }^{21}$. The food are generally coloured yellow, so the colouring agent may interfere the determination of formaldehyde spectrofotometrically with Nash reagent. Hence, the aims of this study is to develop a new lower cost, simple, sensitive, selective, and reproducible formaldehyde determination method using TLC densitometry, which be able to provide a variety of options for researchers to conduct safety surveillance of wet noodles products.

\section{MATERIALS AND METHODS}

\section{Chemicals}

Formaldehyde $35 \%$ solution, acetylacetone, acetic acid glaciale, ammonium acetate, methanol, distilled water, and wet noodles samples. All reagents and chemicals are analytical grade and were obtained from Merck Co. Ltd.. The wet noodles samples were purchased from traditional market in Depok City, West Java, Indonesia.

\section{Preparation of Nash reagent}

Acetylaceton $2 \mathrm{ml}$, acetic acid glaciale $3 \mathrm{ml}$ and ammonium acetate $150 \mathrm{~g}$ were dissolved and diluted with distilled water into $1000 \mathrm{ml}$. The reagent was stored in a dark colored, airtight bottle at $0^{\circ} \mathrm{C}$.

\section{Stock solution and Standars}

Stock solution of formaldehyde $\left(1000 \mathrm{mg} \mathrm{l}^{-1}\right)$ was prepared by diluting $35 \%$ formaldehyde solution with proper quantity of distilled water. Standard solutions of desired concentrations (1-20 mg l-1) were prepared by appropriate dilution of the stock solution.

\section{Sample solution}

Pulverized wet noodles sample was weigh accurately $\pm 0.2 \mathrm{~g}$, added $5.0 \mathrm{ml}$ distilled water, mixed and warmed over water bath $\left(40 \pm 2^{\circ} \mathrm{C}\right)$ for $1 \mathrm{~h}$, allowed to room temperature, added distilled water to the volume of $10.0 \mathrm{ml}$, mixed and centrifuged. The supernatant was used as as the sample solution.

\section{Procedure and analytical conditions}

TLC analysis was performed on aluminium TLC plates coated $(10 \mathrm{~cm} \times 10 \mathrm{~cm})$ with silica gel 60 F254 with $250 \mu \mathrm{m}$ thicknes (Merck, Darmstandt, Germany). Samples/standard solution $1.0 \mathrm{ml}$ was added $1.0 \mathrm{ml}$ Nash reagent, mixed and then warmed over water bath $\left(40 \pm 2^{\circ} \mathrm{C}\right)$ for $30 \mathrm{~min}$. After that, the solution was allowed to room temperature, extracted twice with $1.0 \mathrm{ml}$ chloroform, and spotted the chloroform extract to the plate using Nanomat completed with $2 u L$ capilary tube (Camag, Swiszerland). The distance between each spot was 1 $\mathrm{cm}$. The plates was developed to a distance of about $9 \mathrm{~cm}$ using a mixture of chloroform-methanol $(1: 4 \mathrm{v} / \mathrm{v})$ as mobile phase in a twin-through glass chamber which had been pre-saturated with mobile phase vapours. After drying, the spots was scanned at 412 $\mathrm{nm}$ with Camag® TLC Scanner III in reflectanceabsorbance mode and operated by CATS software. The slit dimensions were $8 \mathrm{~mm} \times 0.4 \mathrm{~mm}$ and the scanning speed was $10 \mathrm{~mm} \mathrm{~s}^{-1}$.

\section{Method Validation}

Validation of the analytical method was 
performed according to ICH Q2 guidelines (2005) ${ }^{22}$, including specificity, linearity, limit of detection (LOD), limit of quantitation (LOQ), precision and accuracy:

\section{Specificity}

The TLC densitometric chromatogram of blank sample, formaldehyde standard and sample addition were compared. The method meets the specific criteria when the chromatogram peak of the formaldehyde spot from sample addition was not interferenced by other components of the sample.

\section{Linearity}

The linearity was evaluated by determining the correlation coefficient $\left(R^{2}\right)$ of linear regression analysis $(y=b x+a)$ of calibration curve constructed between peak area and analyte concentration in the range of $4-40 \mathrm{ng} / \mathrm{spot}$.

\section{Detection and quantitation limit (LOD and LOQ)}

The LOD and LOQ were determined using data of standard deviation of the response and the slope of the calibration curve. LOD and LOQ calculated using the equation of $3.3 \mathrm{\sigma} / \mathrm{S}$ and $10 \sigma / S$, respectively. $\sigma$ is the standard deviation of the $y$-intercept of the regression line. $S$ is the slope of the calibration curve. The LOD and LOQ were confirmed by analyzing the spot of formaldehyde with the LOD and LOQ concentration. The detection limit is expressed in $\mathrm{ng} / \mathrm{spot}$.

\section{Precision}

The precision was performed by repeatability and intermediate presicion. Repeatability (intraday precision) was evaluated by determining the amount of standard formaldehyde at three different concentration levels $(4,20$ and $40 \mathrm{ng} / \mathrm{spot})$ in six replications, while intermediate precision was evaluated by repeating the determination in six replications on two consecutive days. The relative standard deviation (RSD) values for repeatability and intermediate precision were calculated.

\section{Accuracy}

The accuracy was determined by adding known amount of standard formaldehyde solution to blank sample to give concentrations of 4,20 and $40 \mathrm{ng} / \mathrm{spot}$ and was analyzed by the proposed methods. A mean percent recovery obtained from three experiments was calculated.

\section{Formaldehyde analysis in wet noodles samples}

The sample and standard solutions were derivatized with Nash reagent, extracted with chloroform and spotted on the same plate, eluted and analyzed by the proposed methods. Identification of formaldehyde in the samples was performed by comparing the similarity of Rf and UV-Vis spectra of the spots from samples with those from a standard. The amount of formaldehyde was calculated from peak area of the spot againts a calibration curve obtained. Each sample was analyzed in triplicate. The results obtained were expressed as mean of formaldehyde content (\%).

\section{RESULTS AND DISCUSSION}

Noodles are one of the most popular Indonesian foods ${ }^{20}$, unfortunately, this foods is often found to be added formaldehyde illegally, especially those sold in traditional markets ${ }^{21}$. Therefore, safety surveillance of wet noodles should be conducted more intesively. Several analytical methods are available for determination of the compound. However, no report on the determination of the compound in wet noodles using TLC densitometric method after derivatization with Nash reagent. $A$ colour reaction for formaldehyde is described which

Table 1: Intraday and intermediate precision study

\begin{tabular}{lll}
\hline $\begin{array}{l}\text { Formaldehyde } \\
\text { amount (ng/spot) }\end{array}$ & $\begin{array}{l}\text { Intraday precision } \\
(\% \text { RSD) }\end{array}$ & $\begin{array}{l}\text { Intermediate precision } \\
(\% \text { RSD) }\end{array}$ \\
\hline 4.02 & 1,57 & 1,75 \\
20.10 & 1,15 & 1,34 \\
40.20 & 1,38 & 1,46 \\
\hline
\end{tabular}


Table 2: Recovery Study (Accuracy)

\begin{tabular}{llll}
\hline $\begin{array}{l}\text { Formaldehyde } \\
\text { added }(\boldsymbol{\mu} \mathbf{g} / \mathbf{g})\end{array}$ & $\begin{array}{l}\text { Added Found } \\
(\boldsymbol{\mu} \mathbf{g} / \mathbf{g})\end{array}$ & Recovery $(\%)^{\star)}$ & RSD (\%) \\
\hline 2.01 & 1.82 & $90.78 \pm 1.09$ & 1.18 \\
10.05 & 9.55 & $95.03 \pm 1.05$ & 1.11 \\
20.10 & 19.49 & $96.39 \pm 1.36$ & 1.41 \\
& Av recovery & $94.07 \pm 1.17$ & \\
\hline
\end{tabular}

${ }^{*} n=3$<smiles>CC(=O)CC(C)(C)C</smiles>

Fig. 1: The reaction of the Nash method $^{23}$

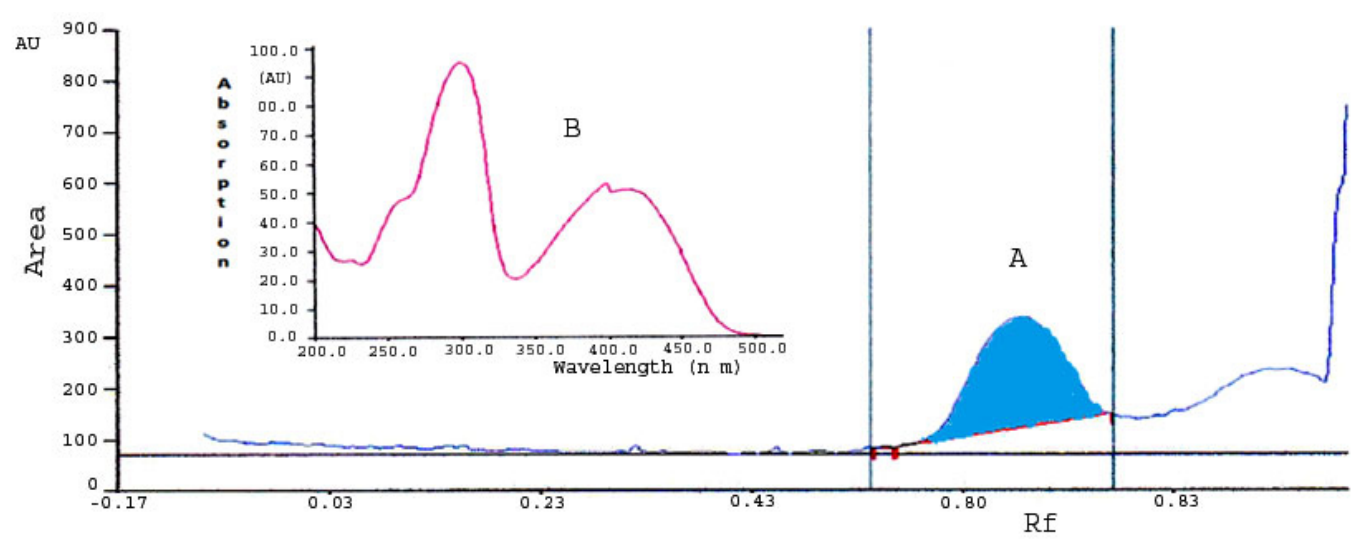

Fig. 2: Chromatogram (A) and spectrum of DDL spot $(B)$ on TLC silica plate $(R f=0.68)$ resulted from formaldehyde reaction with Nash reagent after elution with mixture of chloroform and methanol (1:4).

depends on the synthesis of diacetyldihydrolutidine (DDL) from acetylacetone and formaldehyde in the presence of excess of ammonium salt (Figure 1) $)^{23}$. Its sensitivity and degree of specificity are comparable to those of other reactions requiring more severe conditions ${ }^{9}$. Wet noodles are generally coloured yellow which the colouring agent may interfere the formaldehyde determination spectrophotometrically with Nash reagent, therefore chromatographic seperation was needed to enhance the selectivity of the method.
In this study, formaldehyde standard/ sample solution was derivatized with Nash reagent to give DDL, extracted with chloroform, spotted the chloroform extract to aluminium TLC plates coated $(10 \mathrm{~cm} \times 10 \mathrm{~cm}$ ) with silica gel 60 F254 with 250 $\mu \mathrm{m}$ thicknes and eluted the plate using chloroformmethanol $(1: 4 \mathrm{v} / \mathrm{v})$ as mobile phase.

The chromatograpic system resulted yellow spot at TLC plate and TLC-densitometric analysis resulted chromatogram peak at $\mathrm{Rf} 0.68$ and UV- 


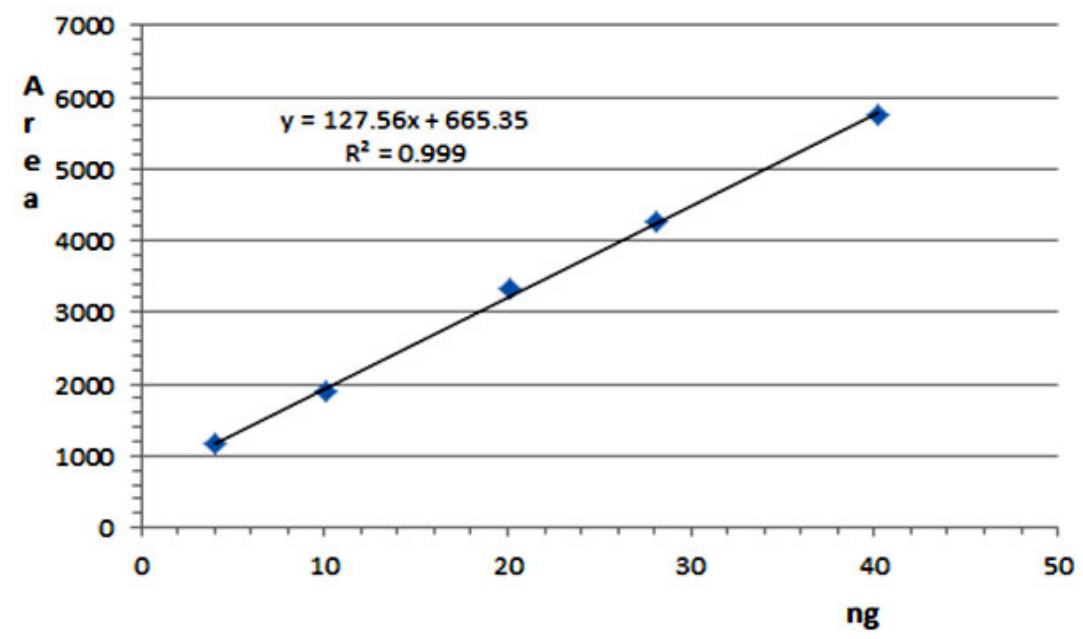

Fig. 3: Calibration Curve of Formaldehyde

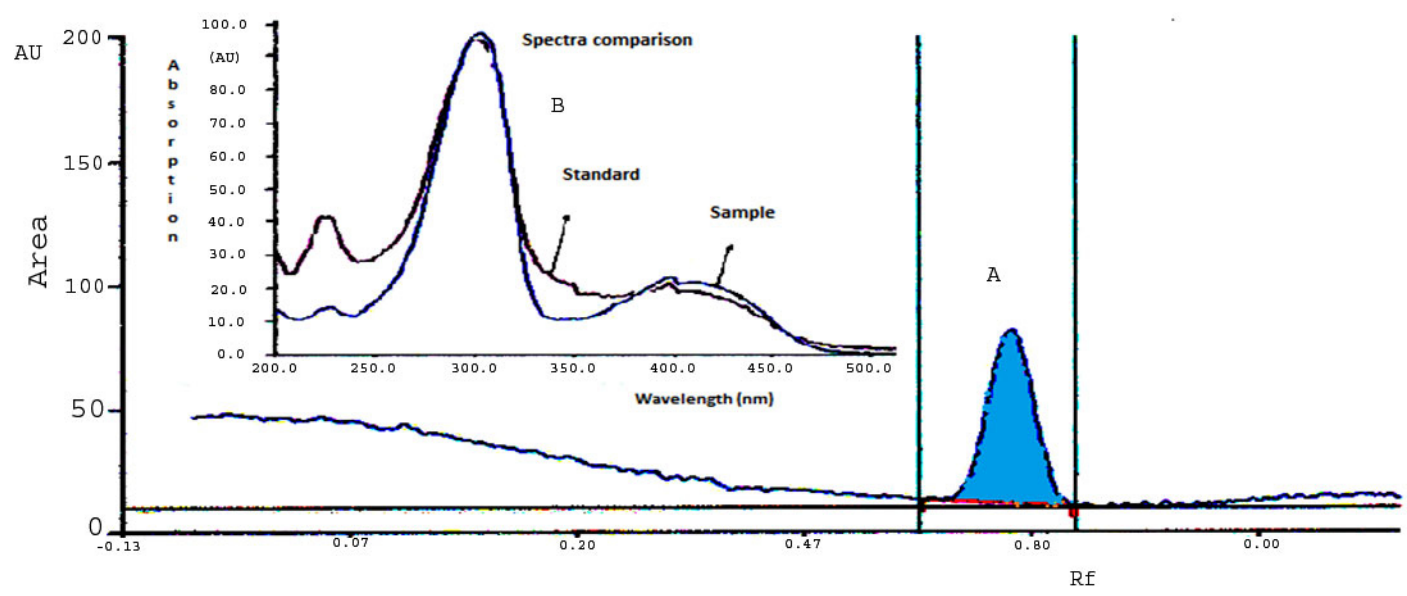

Fig. 4: Profile ofsamplechromatogram (A) and spectra comparison of sample and formaldehyde standard (B) on TLC silica plate analyzed using the proposed method

Table 3: Formaldehyde content in wet noodles samples

\begin{tabular}{lccc}
\hline $\begin{array}{l}\text { Sample } \\
\text { Code }\end{array}$ & $\begin{array}{c}\text { Amount } \\
(\mathbf{m g} / \mathbf{k g})\end{array}$ & SD & RSD (\%) \\
\hline A & 990.94 & 17.50 & 1.77 \\
B & 801.80 & 9.67 & 1.21 \\
C & 1684.36 & 23.45 & 1.39 \\
\hline
\end{tabular}

${ }^{*} n=3$

Vis spectrum having $\lambda \max$ at 300 and $412 \mathrm{~nm}$ (Figure 2). At wavelengths below $350 \mathrm{~nm}$, both Nash reagent and DDL have a very strong absorption peak, while at wavelengths more than $350 \mathrm{~nm}$, the only DDL having an absorption peak, therefore the maximum absorption wavelength of $412 \mathrm{~nm}$ was selected, so the interference of the Nash reagent was effectively avoided ${ }^{7}$. The TLC-densitometric method showed a good selectivity. There was not observed any interference from the sample components at Rf of DDL.

The linear regression analysis of the calibration curve between the amount of formaldehyde and peak area of DDL showed good linear relationship over the concentration range of 4.02-40.20ng/spot. The linear equation: $Y=127.56 \mathrm{X}$ +665.35 with corellation co-efficient $(r)=0.999$. (Figure 3 ). The LOD and LOQ values obtained were 1.75 and $5.29 \mathrm{ng} / \mathrm{spot}$, respectively. 
The precisions of the method were found to be satisfactory as the RSD values determined by repeatability and intermediate precision studies were all less than $2.0 \%$ (Table I). The accuracy of the method was determined from the recovery studies. Recoveries obtained from formaldehyde addition to blank sample ranged from $90.78 \%$ to $96.39 \%$. The RSD was from 1.11-1.41\%(Table II).

\section{Formaldehyde analysis in wet noodles samples}

Results of the analysis of three samples ( $\mathrm{A}, \mathrm{B}$, and $\mathrm{C}$ ) found that all the samples contain formaldehyde with the concentration of 990.94 , 801.80 and $1684.36 \mathrm{mg}$ formaldehyde per $\mathrm{kg}$, respectively (Table III). The chromatogram of the samples had similarity in Rf and UV spectrum with those of formaldehyde standard (Figure 4). The results illustrated the alarming public health situation, particularly since formaldehyde increases the risk of leukemia.

\section{CONCLUSIONS}

The above proposed TLC-densitometric method for the determination of formaldehyde illegally added to wet noodles as preservative was successfully developed. The method gave satisfactory selectivity, linearity, precision and accuracy validation criteria, with lower operating cost, so could therefore be useful to conduct safety surveillance of wet noodles products.

\section{ACKNOWLEDGEMENTS}

The authors are thankful to Faculty of Pharmacy, Universitas Indonesia, Depok, West Java, Indonesia, for providing Laboratory facility.

\section{REFERENCES}

1. Tang,X.; Bai, Y.; Duong, A.; Smith, M.T.; Li, L.; Zhang, L. Environ. Int., 2009, 35, 12101224

2. Schwilk,E.; Zhang, L.; Smith, M.T.; Smith, A.H.; Steinmaus, C. J Occup. Environ. Med., 2010, $52(9), 878-886$

3. Aminah, A, S.; Zailina, H.; Fatimah, A.B. Food and Public Health, 2013, 3(1), 52-58.

4. Jaman, N.; Hoque, M.S.; Chakraborty, S.C.; Hoq, M.E.; Seal, H. P. Int. J. Fish. Aq. Studies, 2015, 2(6), 94-98

5. Norliana,S.; Abdulamir, A. S.;Abubakar, F.; Salleh, A. B. Am. J. Pharmacol. Tox, 2009, 4 (3), 98-106,

6. Purawisastra, S.; Sahara, E.,. J. Nut. Food Res., 2011, 34(1), 63-74

7. Tong,Q.; Song, J.; Li, Q.Adv. Mat. Res., 2012, 554-556, 1493-1497

8. Yeh, T. S.; Lin, T. C.; Chen, C. C.; Wen, H. M. J. Food and Drug Anal., 2013, 21, 190-197.

9. Nash, T. Biochem. J., 1953, 55, 416-421

10. Khanmohammadi, M.; Garmarudi, A. B.; Dalali, N.; Karami, F.; Nemati, H.Bull. Chem. Soc. Ethiop., 2012, 26(2), 299-304.

11. Compton, B. S.; Purdy, W. C.. Anal. Chim. Acta, 1980, 119, 344-357.

12. Georghiou, P. E.; Ho, C. K. J. Can. J. Chem., 1989, 67, 871-876.
13. Al-Moniee, M. A.; Koopal, C.; Akmal, N.; van Veen, S.; Zhu, X.; Sanders, P. F.; Al-Abeedi, F.N.; Amer, A. M. J. Sensor Technol. , 2016, 6, 101-109.

14. Rivero, R. T.; Topiwala, V. J. Cosmet. Sci., 2004, 55, 343-350.

15. Wu, P.W., Chag, C. C.; Chou, S. S. J. Food Drug Anal., 2003, 11, 8-15.

16. Kaale, E.; Risha, P. ; Layloff, T.J. Chromatogr. A, 2011, 1218, 2732-2736

17. Dar, A.; Shaque, U.; Anwar, J.; Zaman, W.; Naseer, A. J. Saudi Chem. Soc., 2016, 20, S352-S356

18. Doroodmand, M. M, Kharekani, M. G; Nezhad, M. D. Sensor Let., 2016, 14 (5), 554-562

19. Rani, R. ; Srivastava, M. M. Nat. Acad. Sc. Let., 2016, 39 (1), 21-24

20. Abidin, A. A.; Devi, C.; Adeline, A., 2013. J. Eng. Technol. Sci., 45 (1), 97-111

21. Gani, A.A., Yuwono, M.; Kuswandi, B. Am. J. Anal. Chem., 2013, 4, 661-667

22. $\mathrm{ICH}$ guidelines. International Conference on Harmonisation Guidelines on Validation of Analytical Procedure: Text and Methodology Q2 (R1), Geneva, 2005, 1-8.

23. Compton, B. S.; Purdy, W.C.,. Can. J. Chem., $1980,58,2207-2211$ 